\title{
CORRIGENDUM
}

\section{Arsenic trioxide (ATO) and MEK1 inhibition synergize to induce apoptosis in acute promyelocytic leukemia cells}

P Lunghi $^{1}$, A Tabilio ${ }^{2}$, F Lo-Coco ${ }^{3}$, P Pelicci $^{4}$ and A Bonati ${ }^{5}$

Leukemia (2005) 19, 322. doi:10.1038/sj.leu.2403642

Correction to: Leukemia (2005), 19, 234-244.

doi:10.1038/sj.leu.2403585

The authors have identified that the name of the coauthor $P$ Pelicci and his affiliation are incomplete. The correct name and affiliation are reproduced here:
PG Pelicci

Department of Experimental Oncology, European Institute of Oncology, Milan, Italy

The authors apologise for any confusion this might have caused. 